\title{
Clinicopathological findings in sea turtles assessed during the Deepwater Horizon oil spill response
}

\author{
N. I. Stacy ${ }^{1,7, *}$, C. L. Field ${ }^{2}$, L. Staggs ${ }^{3}$, R. A. MacLean ${ }^{4}$, B. A. Stacy ${ }^{5}$, J. Keene ${ }^{5}$, \\ D. Cacela ${ }^{6}$, C. Pelton ${ }^{1}$, C. Cray $^{7}$, M. Kelley ${ }^{4}$, S. Holmes ${ }^{3}$, C. J. Innis ${ }^{8}$ \\ ${ }^{1}$ Department of Large Animal Clinical Sciences, College of Veterinary Medicine, University of Florida, 2015 SW $16^{\text {th }}$ Ave, \\ Gainesville, FL 32610, USA \\ ${ }^{2}$ The Marine Mammal Center, 2000 Bunker Road, Sausalito, CA 94965, USA \\ ${ }^{3}$ GulfWorld Marine Park, 15412 Front Beach Road, Panama City Beach, FL 32413, USA \\ ${ }^{4}$ Audubon Nature Institute, 6500 Magazine Street, New Orleans, LA 70118, USA \\ ${ }^{5}$ NOAA, University of Florida (duty station), 471 Mowry Road, Building 471, Gainesville, FL 32611, USA \\ ${ }^{6}$ Abt Associates, Inc. Boulder, CO 80302, USA \\ ${ }^{7}$ Division of Comparative Pathology, Department of Pathology \& Laboratory Medicine, \\ University of Miami School of Medicine, Miami, FL 33101, USA \\ ${ }^{8}$ Animal Health Department, New England Aquarium, Central Wharf, Boston, MA 02110, USA
}

\begin{abstract}
During the BP Deepwater Horizon (DWH) oil spill in 2010, 319 live oiled sea turtles were rescued and admitted to rehabilitation centers for decontamination and veterinary care. Most turtles were small, surface-pelagic juveniles that were collected from oiled habitat distant from shore. Serial hematology, plasma biochemistry, and blood gas analyses were reviewed to characterize abnormalities relative to observed degree of oiling. Clinicopathological abnormalities upon admission indicated acute, nonspecific metabolic and osmoregulatory derangements that were attributable to a combination of events including stress, exertion, physical exhaustion, and dehydration related to oiling, capture, and transport. Specific toxicological effects reported in other taxa were not observed. Initial point-of-care blood data from one rescue center were evaluated using clinical assessment of physiological status for all turtles of all species with available data for $\mathrm{pH}, \mathrm{pCO}_{2}$, sodium, and potassium. In addition, a prognostic model that was specifically developed for cold-stunned Kemp's ridley sea turtles Lepidochelys kempii was applied to oiled Kemp's ridley turtles from one center. Thirty-six percent of oiled turtles were identified as physiologically deranged based on a clinical assessment of their physiological status, and $25 \%$ of oiled Kemp's ridley sea turtles exceeded the mortality risk threshold of the prognostic model. These results indicate that the physiological derangements in these animals were relatively severe and clinically relevant. Based on observations during the DWH spill, adverse physiological effects in sea turtles may be an important consequence of stress, exertion, physical exhaustion, and dehydration secondary to oiling, capture, and transport.
\end{abstract}

KEY WORDS: Acid-base · Hematology $\cdot$ Chemistry $\cdot$ Clinical pathology $\cdot$ Deepwater Horizon · Oil spill $\cdot$ Sea turtle

\section{INTRODUCTION}

The BP Deepwater Horizon (DWH) oil spill in 2010 contaminated a vast area of the Gulf of Mexico. Five species of sea turtle, i.e. Kemp's ridley

\footnotetext{
*Corresponding author: stacyn@ufl.edu
}

Lepidochelys kempii, green Chelonia mydas, loggerhead Caretta caretta, hawksbill Eretmochelys imbricata, and leatherback Dermochelys coriacea turtles, are found within the region and all are protected under the US Endangered Species Act.

(c) The authors and (outside the USA) the US Government 2017. Open Access under Creative Commons by Attribution Licence. Use, distribution and reproduction are unrestricted. Authors and original publication must be credited. 
Hundreds of live oiled turtles were recovered by spill response operations and were taken to designated wildlife rehabilitation facilities for veterinary care and treatment. Nearly all of these oiled turtles were surface-pelagic juveniles rescued from oiled areas many kilometers from shore (Stacy 2012). Upon admission to care facilities, turtles were evaluated, stabilized with supportive care as necessary, and cleaned of oil. Clinical evaluation during the course of rehabilitation included physical examinations, blood gas analyses, serial hematology and blood chemistry, as well as other clinically indicated diagnostic tests.

Little information is available on the effects of petroleum and dispersants (e.g. Corexit 9500, Corexit 9527) on sea turtles, especially during oil spills. Oiling of sea turtles has been reported during several previous oil spills, but the published details generally have been limited to numbers or estimates of animals oiled, species, and life stage (reviewed by Shigenaka 2003). Vargo et al. (1986) exposed juvenile loggerheads to crude oil and studied both pathological and behavioral effects, some of which were later published by Lutcavage et al. (1995). Much of the remaining literature relates to sporadic strandings of sea turtles oiled by unidentified sources or ingestion of floating tar balls, which are well-recognized threats to post-hatchling and pelagic juvenile sea turtles (Witherington 2002, Orós et al. 2004, Camacho et al. 2013). Based on these reports, the potential effects of petroleum exposure generally are believed to be multi-systemic and significant, but are incompletely defined.

These knowledge gaps create challenges in planning for emergency intervention during oil spills more information on anticipated health problems would lead to better informed and better provisioned response efforts for affected wildlife. In addition, an understanding of the effects of oil exposure is fundamental to estimating the full scope of the resulting harm to wildlife. The efforts to rescue and rehabilitate oiled sea turtles during the DWH spill were unprecedented in scale and yielded a large amount of information on the effects of oiling on sea turtles. This information is not only valuable for responses to future spills, but is relevant to the fate of the estimated tens of thousands of sea turtles that were oiled during the DWH spill but were not rescued (McDonald et al. 2015).

The objective of this study was to evaluate clinicopathological data from oiled turtles rescued during the DWH spill in order to characterize the clinical status and blood analytes upon admission and dur- ing rehabilitation. An extensive dataset of clinical information collected from oiled turtles was reviewed to describe abnormalities and compare findings among turtles with various observed degrees of oiling. In addition, a clinical assessment of physiological status and a prognostic model based on basic physiological parameters shown to be predictive of mortality of cold-stunned Kemp's ridley sea turtles was applied to admission blood values for oiled turtles in order to consider the potential fate of oiled animals that remained at sea and did not receive care.

\section{MATERIALS AND METHODS}

\section{Recovered sea turtles}

Sea turtles were rescued by capture crews aboard vessels dispatched into the northern Gulf of Mexico under official spill response operations during the DWH spill (Stacy 2012). These crews targeted offshore convergence fronts created by wind and ocean currents, especially those containing Sargassum communities, which are important habitat for surface-pelagic juvenile sea turtles and which also accumulated floating oil during the DWH spill (McDonald et al. 2015). Turtles were transported by vehicle from ports to 2 high-capacity rehabilitation facilities, hereafter referred to as Facility A (Audubon Nature Institute, New Orleans, LA, USA) and B (GulfWorld Marine Park, Panama City Beach, FL, USA), which were equipped with hazardous material containment. Transportation times in vehicles were approximately $1.5 \mathrm{~h}$ to Facility A, and 1.0 or $2.8 \mathrm{~h}$ to Facility $\mathrm{B}$ (depending on port of origin).

Following initial care and stabilization at these facilities, most sea turtles were transferred to secondary facilities for additional rehabilitation prior to release. After the conclusion of wildlife response operations, medical records from all facilities were compiled, reviewed, and entered into a Microsoft Access database for analysis.

\section{Oiling categories, clinical evaluation, treatment}

Photographs and records of rescued turtles were previously reviewed to assign turtles into oiling categories (OCs) based on visual assessment (Stacy 2012). Briefly, OCs were defined as 1 to 4, based on photographs taken immediately after capture and before removal of oil in the field: (1) minimally oiled: 
oil was either limited to one region of the body or coverage was very light (thin smear or staining only); (2) lightly oiled: a thin layer of oil lightly covered multiple parts of the body, and thicker aggregated oil, if present, was focally distributed; (3) moderately oiled: heavier layers of oil covered multiple areas of the body, often accompanied by generalized brown staining; (4) heavily oiled: aggregates of thick, tenacious oil diffusely covered the body.

Upon admission, turtles were weighed, measured (straight carapace length from nuchal notch to supracaudal scute $=$ SCL) and physically examined. Each facility developed protocols for cleaning and medical treatment of turtles upon admission. De-oiling treatment at both facilities included 1 or multiple external cleanings (using vegetable oil, mayonnaise, and mild liquid detergent) within the first week after admission, as well as oral administration of menhaden oil or cod liver oil with mayonnaise for most turtles. Activated charcoal was used in a small number of turtles $(\mathrm{n}=15-20)$ that were admitted in the early phase of the oil spill response but was discontinued due to regurgitation. Turtles received fluid therapy and Vitamin B complex as standard treatment at admission and, when indicated, iron and/or calcium supplementation. In addition, turtles at Facility A were treated with injectable antibiotics (ceftazidime; $20 \mathrm{mg} \mathrm{kg}{ }^{-1}$ i.m. every $3 \mathrm{~d}$ for at least $2 \mathrm{wk}$ ). Additional medical treatments were provided at the discretion of attending veterinarians and were noted in the medical record of each individual turtle.

\section{Blood processing and analysis}

After initial examination, but prior to bathing and therapeutic intervention, blood was collected from an external jugular vein for immediate blood gas analysis (handheld point-of-care analyzer) and then transferred into lithium-heparin. From the heparinized whole blood, 1 aliquot was removed for hematology, and the remainder of the sample was centrifuged $(10 \mathrm{~min}$ at $5000 \times g)$ to harvest plasma. Whole blood and plasma samples were then shipped overnight on cold packs for submission to veterinary diagnostic laboratories (University of Miami Avian and Wildlife Laboratory, Miami, FL, USA, and Antech Diagnostics $\left({ }^{\circledR}\right)$ for hematological and plasma biochemical analysis. Blood samples were collected from the majority of turtles at admission and at different time points during rehabilitation as considered needed for an individual animal based on the veterinarian's discretion.
Facilities A and B both used the handheld i-STAT analyzer (VetScan, Abaxis) for immediate blood analysis using available test cartridges (CG4+, CG8+, and EC8+ cartridges), which included various panels of blood gas, electrolyte, and biochemical analyte combinations, including the following: $\mathrm{pH}, \mathrm{pCO}_{2}$, $\mathrm{pO}_{2}$, sodium $(\mathrm{Na})$, potassium $(\mathrm{K})$, chloride $(\mathrm{Cl})$, ionized calcium (iCa), glucose (Glc), lactate, bicarbonate (Bicarb), blood urea nitrogen (BUN), and anion gap (AG). Osmolality (Osm) and AG were also manually calculated using established formulas (Stockham \& Scott 2008). Since the analyzer performs analyses at $37^{\circ} \mathrm{C}$, temperature corrections were used to adjust for the individual turtle's cloacal temperature. Blood gas values were either temperature-corrected by the analyzer (hereafter referred to as 'autocorrected') or, if autocorrected values were not available, temperature-corrected blood gas results were calculated based on published equations (Innis et al. 2007, Keller et al. 2012). If body temperature was not recorded, the mean cloacal temperature of $27.0^{\circ} \mathrm{C}$ was used for blood gas calculations at admission and the subsequent time intervals. A higher mean of $29.0^{\circ} \mathrm{C}$ was used for initial blood gas corrective calculations for Facility A turtles which had a higher cloacal temperature at admission (Supplementary Materials [SM] I Table 32 \& SM III Fig. 32, www.int-res.com/articles/ suppl/n033p025_supp/).

Hematological analysis included centrifugation of a capillary tube $(3000 \times g$ for $3 \mathrm{~min})$ to obtain packed cell volume (PCV), plasma color, and total solids by refractometer; red blood cell (RBC) and white blood cell (WBC) counts (Unopette $\circledR_{\text {, Becton- }}$ Dickinson, Becton-Dickinson Diagnostics, Pre-analytical Systems); hemoglobin concentration ( $\mathrm{Hb})$ (cyan-methemoglobin method); and blood film evaluation (WBC differential and blood cell morphology). At least 2 blood films were made directly after each blood sample collection and archived for each animal. A subset of selected blood smears was evaluated after staining with Romanowsky-type based stain (Wright-Giemsa) when considered necessary, mostly for the purpose of investigation of animals with low PCV. Unstained blood smears of selected moderate to severe anemia cases were stained with New Methylene Blue (New Methylene Blue N, LabChem) to investigate potential causes of anemia (e.g. evidence of oxidative damage to erythrocytes).

Plasma biochemical analysis included alanine aminotransferase (ALT), albumin (ALB), aspartate aminotransferase (AST), alkaline phosphatase (ALP), $\mathrm{BUN}, \mathrm{Ca}, \mathrm{Cl}$, cholesterol (CHOL), creatine kinase 
(CK), globulins (GLOB), Glc, lactate dehydrogenase $(\mathrm{LDH}), \mathrm{K}$, phosphorus (P), Na, total protein (TP), triglycerides (TRIG), and uric acid (UA). Plasma chemistry was performed using a dry chemistry analyzer (Ortho Clinical Diagnostics) at the University of Miami Avian and Wildlife Laboratory for turtles treated at Facility A, or a Beckman Olympus AU5431 at Antech Diagnostics@ for turtles treated at Facility B.

Clinicopathological data of each individual were grouped into defined time intervals, which extended to the length of each individual's rehabilitation period. This step was necessary because samples were not taken at standard time points among all turtles admitted to rehabilitation facilities. The values were grouped as follows: admission, Days 1 to 2, Days 3 to 5, Days 6 to 10, Days 11 to 20, Days 21 to 30, Days 31 to 40, Days 41 to 50, Days 51 to 60, Days 61 to 70 , Days 71 to 80, Days 81 to 90, Days 91 to 100, Days 101 to 150, Days 151 to 200, Days 201 to 250, Days 251 to 300, and Days 301 to 360. If multiple samples were collected from a particular individual within a certain time period, the average of results obtained during the time period was used to represent that individual in that period for statistical analyses.

It is important to note that the data analyzed herein were collected during a large-scale, emergency wildlife rescue response, not a research study. Blood analysis results were not available for all turtles at each time period; therefore, the number of available results in the summary tables for each facility varies. After admission, the next interval with the most available results was Days 11 to 20. Since the majority of turtles were sampled shortly before release or transfer to a secondary rehabilitation facility, time intervals with the next highest number of available results were Days 51 to 60 for Facility A and Days 31 to 40 for Facility B.

Limited published hematology and chemistry reference ranges are available for surface-pelagic juvenile sea turtles; thus, the interpretation of blood abnormalities was based on published data from convalescent Kemp's ridley sea turtles (Innis et al. 2007, 2009, Keller et al. 2012), green turtles (Bolten \& Bjorndal 1992, Anderson et al. 2011), and loggerhead turtles (Casal et al. 2009, Kelly et al. 2015). The reported data of these studies were extrapolated to produce clinically reasonable analyte ranges for surface-pelagic immature turtles.

Juvenile loggerhead sea turtles tend to have lower PCV values (median $28 \%$; range 17-45\%) than adult loggerheads (median $40 \%$; range $28-54 \%$, Casal et al. 2009). Another study reported a PCV range of 9-40\% (median $31 \%$ ) in healthy juvenile loggerhead turtles (Kelly at al. 2015). Therefore, we considered surface-pelagic juvenile sea turtles to be anemic if the PCV was less than $20 \%$, and we characterized the degree of anemia as mild (16-19\%), moderate $(11-15 \%)$, or marked $(\leq 10 \%)$. Based on the above listed references and clinical experience, we considered WBC and heterophils elevated if concentrations were above 15000 or $9000 \mathrm{\mu l}^{-1}$, respectively, with additional quantification of mild (15000 to $19999 \mu^{-1}$ WBC, 9000 to $14999 \mu^{-1}$ heterophils), moderate (20000 to $29999 \mathrm{\mu l}^{-1} \mathrm{WBC}, 15000$ to $24999 \mathrm{\mu l}^{-1}$ heterophils), and marked $\left(\geq 30000 \mathrm{\mu l}^{-1}\right.$ WBC, $\geq 25000 \mathrm{\mu l}^{-1}$ heterophils) degrees. Glucose ranges for juvenile sea turtles were considered to be normal within the range of 80 to $140 \mathrm{mg} \mathrm{dl}^{-1}$.

\section{Statistical analysis of hematology and blood chemistry data}

Results of all blood analyses from the initial and secondary facilities were reviewed, spanning the entire duration of captivity; however, statistical analyses primarily focused upon results from the initial intake Facilities A and B to reduce variability inherent to differences in sample handling and processing protocols, different instrumentation, and the use of different analytical laboratories. Due to these differences, results from Facilities A and B were summarized separately by species and time period.

Means, medians, standard deviation, and range were determined for each blood analyte for OCs 1 to 4. One-way analysis of variance (ANOVA) was used to test the null hypothesis of no differences among OCs 1 to 4 for blood chemistry and hematology parameters. All statistical comparisons were assessed separately for each interval. Measurements derived using different types of i-STAT test cartridges were pooled. For analytes that were measured using both i-STAT and other methods, results were analyzed separately. In cases where ANOVA indicated a significant difference $(p<0.05)$ for the test of equality among OCs, Tukey's HSD test was conducted to test for pairwise equality between each OC. It was common for individual turtles to be sampled repeatedly through the course of rehabilitation. For this reason, blood chemistry and hematology analytes were also assessed by estimating mixed effects models that included elapsed time (days since admission), OC, and their interaction as main effects to quantify trends over time and to assess differences among OCs in a comprehensive manner. All statistical analyses were performed with R (R Core Team 2015), Microsoft Excel, and Analyse-it 2.26 Software. 


\section{Clinical assessment of physiological status}

Medical records were reviewed to evaluate the clinical physiological status of oiled sea turtles upon admission. We only used data from Facility $\mathrm{A}$ in this step to reduce variability created by different analytical laboratories and instrumentation, as well as confounding differences such as duration of ground transport and other differences in facility protocols. Furthermore, turtles admitted to Facility A were representative of all OCs, whereas moderately and heavily oiled turtles were underrepresented or were not represented, respectively, at Facility B.

Variables of interest for the clinical assessment of physiological status included temperature-corrected $\mathrm{pH}$ and partial pressure of $\mathrm{CO}_{2}\left(\mathrm{pCO}_{2}\right)$, as well as $\mathrm{Na}$ and $\mathrm{K}$ at time of admission. The degree of derangements of these 4 variables was evaluated by a board certified reptile specialist with substantial sea turtle clinical experience (C.J.I.) to categorize each individual sea turtle as either ' 1 ' = 'physiologically deranged' or ' 2 ' = 'stable.' The category of physiologically deranged was defined as a turtle that likely benefited from veterinary intervention based on the suite of clinicopathological abnormalities for that individual. For example, a combination of moderate abnormalities (e.g. $\mathrm{pH}<7.4, \mathrm{pCO}_{2}>40 \mathrm{~mm} \mathrm{Hg}$, and $\mathrm{K}>$ $5.0 \mathrm{mmol} \mathrm{l}^{-1}$ ) or a more significant derangement of 1 analyte (e.g. $\mathrm{K}=7.8 \mathrm{mmol}^{-1}$ ) categorized a turtle as physiologically deranged. This assignment of a turtle to the physiologically deranged category was done conservatively, and generally resulted from moderate to severe derangements of multiple parameters.

\section{Prognostic scoring model}

A prognostic scoring model developed for coldstunned Kemp's ridley sea turtles in a previous study found that venous blood $\mathrm{pH}_{1} \mathrm{pO}_{2}$, and $\mathrm{K}$ were the most predictive of mortality (Stacy et al. 2013). In that study, various scoring models were developed as an objective measure of blood analyte derangements in cold-stunned turtles. The combination of $\mathrm{pH}_{1} \mathrm{pO}_{2}$, and $\mathrm{K}$ derangements in that study provided the best diagnostic performance to predict mortality with a sensitivity of $88 \%$ and a specificity of $80 \%$, respectively, and an area under the curve of 0.896 (95\% confidence interval: 0.83-0.94) using receiver operating characteristics. According to the severity of derangement for each analyte, points were assigned. The points resulting from assessment of each analyte were then added, resulting in a sum score. If the score exceeded a calculated threshold, the animal was categorized as being at risk for mortality.

This model is the only prognostic scoring model available in the current literature for sea turtles with a specific condition, i.e. hypothermia, a condition that often results in mortality despite medical care. To assess the relative severity of physiological abnormalities observed in oiled turtles, we adapted this prognostic scoring model using the combination of $\mathrm{pH}, \mathrm{pO}_{2}$, and $\mathrm{K}$ derangements to data collected from turtles upon admission to Facility A using the same definitions for degree of blood analyte abnormalities. Furthermore, use of this model was restricted to Kemp's ridley turtles, the only species for which this model has been validated.

The outcomes of the clinical assessment of physiological status and application of the model were compared between OCs by numerical score using Kruskal-Wallis 1-way ANOVA. The p-values were considered significant at $<0.05$.

\section{RESULTS}

\section{Summary information, rehabilitation duration, and outcome}

Kemp's ridley turtles comprised the majority of animals admitted $(60 \%, 192 / 319)$, followed by green turtles $(35 \%, 113 / 319)$, loggerhead turtles $(3 \%, 9 / 319)$, and hawksbill turtles $(2 \%, 5 / 319)$. Most of the turtles were surface-pelagic juveniles with a mean SCL of less than $25 \mathrm{~cm}$. Transfer to secondary facilities was on average $72 \mathrm{~d}$ (range 39-136 d) for Facility A and $10 \mathrm{~d}$ (range 3-31 d) for Facility B after admission. The mean rehabilitation interval was 98 d (range 30360 d). Turtles gained an average of $39 \%$ in body weight at both facilities during the rehabilitation interval, as expected in young, growing animals on a captive diet. Total numbers of medical records of oiled turtles reviewed are summarized by facility, species, and OC in Table 1.

Four turtles died after admission; all other turtles were successfully rehabilitated and eventually released. Three Kemp's ridley turtles died from severe hyponatremia (<100 mmol $^{-1}$ ) within $4 \mathrm{~d}$ after admission likely caused by fluid overload related to excessive freshwater exposure. Less likely possible considerations for the cause of death of these 3 turtles included fluid therapy and/or effects of oil exposure on fluid regulatory function. One green turtle was euthanized in a moribund state $142 \mathrm{~d}$ after admission due to severe bacterial colitis. 
Table 1. Summary of all oiled recovered sea turtles admitted to Facility A (Audubon Nature Institute) and Facility B (Gulf World Marine Park) by oiling category and species (Lk: Kemp's ridley sea turtle Lepidochelys kempii; CM: green turtle Chelonia mydas; Cc: loggerhead sea turtle Caretta caretta; Ei: hawksbill sea turtle Eretmochelys imbricata). Oiling categories included 1 (minimally oiled), 2 (lightly oiled), 3 (moderately oiled), and 4 (heavily oiled)

\begin{tabular}{|c|c|c|c|c|}
\hline Species & $\begin{array}{l}\text { Oiling } \\
\text { category }\end{array}$ & All & $\begin{array}{c}\text { Facility } \\
\text { A }\end{array}$ & $\begin{array}{c}\text { Facility } \\
\text { B }\end{array}$ \\
\hline \multirow[t]{5}{*}{ All } & 1 & 139 & 34 & 105 \\
\hline & 2 & 76 & 48 & 28 \\
\hline & 3 & 46 & 36 & 10 \\
\hline & 4 & 58 & 58 & 0 \\
\hline & Total & 319 & 176 & 143 \\
\hline \multirow[t]{5}{*}{$\mathrm{Lk}$} & 1 & 73 & 17 & 56 \\
\hline & 2 & 46 & 29 & 17 \\
\hline & 3 & 25 & 17 & 8 \\
\hline & 4 & 48 & 48 & 0 \\
\hline & Total & 192 & 111 & 81 \\
\hline \multirow[t]{5}{*}{$\mathrm{Cm}$} & 1 & 62 & 16 & 46 \\
\hline & 2 & 28 & 18 & 10 \\
\hline & 3 & 17 & 15 & 2 \\
\hline & 4 & 6 & 6 & 0 \\
\hline & Total & 113 & 55 & 58 \\
\hline \multirow[t]{5}{*}{$\mathrm{Cc}$} & 1 & 3 & 0 & 3 \\
\hline & 2 & 1 & 1 & 0 \\
\hline & 3 & 3 & 3 & 0 \\
\hline & 4 & 2 & 2 & 0 \\
\hline & Total & 9 & 6 & 3 \\
\hline \multirow{5}{*}{$\mathrm{Ei}$} & 1 & 1 & 1 & 0 \\
\hline & 2 & 1 & 0 & 1 \\
\hline & 3 & 1 & 1 & 0 \\
\hline & 4 & 2 & 2 & 0 \\
\hline & Total & 5 & 4 & 1 \\
\hline
\end{tabular}

\section{Clinicopathological data}

The observed clinicopathological abnormalities in oiled turtles reflected nonspecific, acute metabolic and osmoregulatory derangements at time of admission to rehabilitation facilities. The presence and trends of physiological derangements were mostly similar in oiled turtles admitted to Facilities A and B, but were more pronounced at Facility B likely due to differences in capture, longer transport times, handling, and blood analytical methodology differences. While mainly lightly oiled turtles were admitted to Facility B, turtles of Facility A were representative of all OCs, thus allowing for a meaningful comparison among all OCs.

Given the size and complexity of this dataset, the discussion of results focuses on the more clinically relevant variations and significant differences of blood analytes. Mean, median, standard deviation, and range for each parameter are presented by OCs 1 to 4 and by facility and species in the Supplementary Materials (SM I Tables 1-44 and SM II Figs. [box plots] $1-44$; mixed effects model results are summarized in SM III Figs. 1-44).

\section{Hematological findings}

PCV data were within normal limits in the majority of turtles upon admission and did not show any statistically significant trends (SM I Tables $1 \& 2$ and SM III Figs. $1 \& 2$ ) over time or across OCs at Facility A and Facility B, respectively. The PCV data were mirrored in similar trends in $\mathrm{RBC}$ count and $\mathrm{Hb}$ concentration (SM I Tables 3 \& 4, SM III Figs. 3 \& 4), although with significant decreasing trends at Facility $\mathrm{B}$ over time (RBC count, $\mathrm{p}=0.031 ; \mathrm{Hb}, \mathrm{p}<0.0001$ ) and across OCs (RBC count, $\mathrm{p}=0.027 ; \mathrm{Hb}, \mathrm{p}=0.036$ ). These decreasing trends of RBC count and $\mathrm{Hb}$ at Facility B reflect data from a single Kemp's ridley turtle of OC3 with clinically suspected enteritis, which eventually recovered. Plasma samples showed evidence of hemolysis for 17 turtles upon admission at Facility A and 14 turtles at Facility B, and $<5$ turtles per later time period. Concurrent anemia was not noted, suggesting that hemolysis was likely artefactual from sample collection or handling.

Anemia was observed in 21 of 319 turtles upon admission to both facilities (Table 2). Nineteen of these turtles recovered from the anemia by Days 11 to 20, except for 2 turtles, which convalesced by Day 101. The cause of anemia was not determined in the majority of cases. Causes attributed at any time point at both facilities included pneumonia $(n=2)$, osteomyelitis $(n=1)$, trauma $(n=3)$, presumptive gastrointestinal disease $(n=4)$, or chronic disease $(n=3)$.

Blood smear evaluation of selected animals with anemia at admission, and those animals that developed anemia during rehabilitation, revealed minimal to moderate degrees of RBC regeneration based on morphological evaluation of RBC upon blood films

Table 2. Packed cell volume (PCV) of oiled sea turtles with anemia $(n=21)$ at admission to Facilities A and B. Oiling categories (OC) are defined in Table 1

\begin{tabular}{|lccccc|}
\hline PCV $(\%)$ & OC 1 & OC 2 & OC 3 & OC 4 & Total \\
\hline $16-19$ & 6 & 3 & 3 & 1 & 13 \\
$11-15$ & 2 & 2 & 1 & 2 & 7 \\
$\leq 10$ & 0 & 0 & 1 & 0 & 1 \\
\hline
\end{tabular}


(e.g. increased anisocytosis, polychromasia, basophilic stippling, mitotic figures, and/or immature RBC precursors). However, blood film evaluation may not have revealed regenerative responses in some turtles because blood samples were collected as long as 2 mo after initial detection of anemia, often due to clinical concerns related to repeated blood collection. Blood smears of 28 anemic turtles were stained with New Methylene Blue (Harvey 2012). No Heinz bodies were observed within the erythrocyte cytoplasm.

Total WBC were mildly (49 of 319), moderately (36 of 319), or markedly (5 of 319) increased in 90 of 319 turtles upon admission to both facilities, as characterized by concurrent heterophilia. These observations are demonstrated in SM I Tables $5 \& 6$ and SM III Figs. 5 \& 6, with significant decreasing trends over time for WBC and heterophils at both facilities $(\mathrm{p}<$ 0.0001 for WBC and heterophils at both facilities). These trends did not differ significantly between OCs. WBC and heterophils normalized by Days 11 to 20 for 80 turtles, and the remaining 10 turtles normalized by Days 21 to 30. In addition, slight upward trends over time of lymphocytes at Facility A $(\mathrm{p}<$ $0.001)$, monocytes at Facility B $(p<0.001)$, and eosinophils at both facilities $(\mathrm{p}<0.001)$ were observed (SM I Tables 7-9 and SM III Figs. 7-9), without any differences by $\mathrm{OC}$.

\section{Plasma biochemistry analyses}

Mild upward trends of total solids, TP, ALB, and GLOB were observed over time at both facilities, but values were within expected ranges (SM I Tables 11-14 and SM III Figs. 11-14) with variably significant trends: total solids at Facility A increased over time $(\mathrm{p}<0.001)$; TP increased at both facilities over time $(\mathrm{p}<0.001)$ and differed by OC at Facility A $(p=0.023) ;$ ALB increased over time at Facility B $(p<0.001)$; and ALB differed by OC at Facility A $(\mathrm{p}<0.010)$.

Both elevated and decreased blood glucose concentrations were observed in oiled sea turtles. Hyperglycemia was detected in 64 of 176 of turtles admitted to Facility A and in 94 of 143 at Facility B. A considerable number of turtles had hypoglycemia, including 46 of 176 at Facility A and 10 of 143 at Facility B. Glucose concentrations stabilized within $5 \mathrm{~d}$ after admission with significantly decreasing trends over time but not by OC at both facilities ( $p<0.001$; SM I Table 15 and SM III Fig. 15).

Ca remained stable over time at Facility $A$, with a decreasing trend at Facility B $(p<0.001)$ and a decreasing trend for $\mathrm{iCa}$ at both facilities over time (Facility A, p = 0.01; Facility $\mathrm{B}, \mathrm{p}=0.02$ ), while $\mathrm{P}$ steadily and significantly increased over time at both facilities $(p<0.001)$ with a significant difference among OCs at Facility A ( $p=0.006)$ (SM I Tables 16-18, SM III Figs. 16-18). The Ca:P ratio exhibited significant decreasing trends over time at both facilities $(p<0.001)$, but not by OC. Since dietary species differences need to be considered when interpreting Ca:P ratio data, all 4 species were evaluated separately by mixed modeling effects for this parameter, and the following significant trends over time were observed: green turtles trended slightly upward at Facility A $(p<0.001)$ and slightly downward at Facility B $(p=0.01)$; Kemp's ridleys trended downwards at both facilities $(p<0.001)$; and there were no trends over time for loggerhead and hawksbill sea turtles. The only significant difference across OCs for the Ca:P ratio was observed in Kemp's ridleys at Facility $B(p=0.021)$.

$\mathrm{Na}, \mathrm{Cl}$, and $\mathrm{K}$ were variably increased or decreased at admission and stabilized by Days 11 to 20 (SM I Tables 19-21, SM III Figs. 19-21). Significant decreasing trends were observed for $\mathrm{Na}$ over time at both facilities $(\mathrm{p}<0.001)$ and for $\mathrm{Cl}$ at Facility A $(p<0.001)$. Plasma K increased over time $(p<0.001)$ and across OCs $(\mathrm{p}=0.014)$ at Facility A, but whole blood $\mathrm{K}$ by i-STAT analysis trended downwards at both facilities (Facility A, p $=0.008$; Facility B, $\mathrm{p}<0.001$ ). In addition, electrolytes by i-STAT analysis (SM I Tables 37-39, SM III Figs. 37-39) exhibited a decreasing trend for $\mathrm{Na}$ at Facility $\mathrm{B}(\mathrm{p}<0.001)$, and at Facility A across OCs for $\mathrm{Na}(\mathrm{p}<0.001)$.

UA increased over time $(p=0.002)$ and BUN had variable trends that were increasing in $\mathrm{OC} 2$ but decreasing in $\mathrm{OC} 1,3$, and $4(\mathrm{p}=0.019)$ at Facility A (SM I Tables 22 \& 23, SM III Figs. 22 \& 23). The manually calculated osmolality based on i-STAT data (SM I Table 44, SM III Fig. 44) showed a decreasing trend at Facility B $(\mathrm{p}=0.04)$.

Cholesterol concentrations varied over time $(\mathrm{p}=$ $0.015)$ and across OCs $(\mathrm{p}=0.047)$ at Facility $\mathrm{A}(\mathrm{p}=$ $0.014)$ and decreased steadily at Facility $B(p=0.016)$, while triglycerides increased over time at both facilities (Facility A, p = 0.059; Facility B, p = 0.043) (SM I Tables $24 \& 25$, SM III Figs. $24 \& 25$ ).

The tissue enzymes ALP, ALT, AST, CK, and LDH showed great variability with various significant differences over time and across OCs (SM I Tables 26-30, SM III Figs. 26-30).

Iron did not exhibit any significant differences over time or by OC at either facility (SM I Table 31, SM III Fig. 31). 


\section{Blood gas analyses}

Blood gas abnormalities were observed in $78 \%$ (114 of 147) of turtles admitted to Facility A and in $96 \%$ (121 of 126) of turtles admitted to Facility B, with the majority presenting with various degrees of mild to severe acidemia. As previously noted, blood gas calculations were temperature-corrected and based on patient or ambient temperature. Measurements of patient temperature showed a significantly decreasing trend over time at Facility A (p < 0.001) (SM I Table 32, SM III Fig. 32). Since available cartridges only allowed for a limited number of concurrent bicarbonate, AG, and lactate measurements, full characterization of blood gas disorders was not possible for all turtles (SM I Tables 33-36, SM III Figs. 33-36). However, the observation of acidemia with concurrent hyperkalemia in 110 turtles at Facility A and 120 turtles at Facility B is most consistent with metabolic acidosis. Respiratory acidosis characterized by concurrent acidemia and hypercapnia was present in 27 turtles at Facility A and in 89 turtles at Facility B. Since bicarbonate concentrations were within normal limits in the majority of turtles, it can be concluded that mixed acid-base disorders (e.g. respiratory and metabolic acidosis with variable compensation) were likely present in many turtles. Four turtles at Facility A and 1 turtle at Facility B had respiratory alkalosis as characterized by alkalemia and hypocapnia. Blood gases of the majority of turtles with initial blood gas abnormalities normalized rapidly within the first week after admission. At both facilities, an increasing trend was observed for $\mathrm{pH}$ over time $(\mathrm{p}<0.001)$ and for Facility A also across OCs $(p=0.007)$. The following additional significant trends were identified: $\mathrm{pO}_{2}$ increased over time at Facility $\mathrm{A}(\mathrm{p}<0.001)$ but remained stable at Facility $\mathrm{B}, \mathrm{pCO}_{2}$ decreased steadily over time at Facility B ( $p<0.001)$, and bicarbonate increased over time at both facilities (Facility $\mathrm{A}, \mathrm{p}=0.031$; Facility $\mathrm{B}, \mathrm{p}=0.002$ ) with a difference across OCs at Facility A $(p=0.002)$. AG and limited lactate data did not reveal any significant mixed model effect observations.

\section{Clinical assessment of physiological status and prognostic scoring model}

Out of 144 turtles of all species with complete data available for analysis from Facility A, 52 were scored as physiologically deranged, equal to $36 \%$ of turtles (Table 3). There were no significant differences in clinical assessments among OCs 1 through 4 (p =
Table 3. Oiled sea turtles of all species admitted to Facility A identified as physiologically deranged (PD) or stable based on clinical assessment using available data for $\mathrm{pH}, \mathrm{pCO}_{2}$, sodium, and potassium $(\mathrm{n}=144)$. Oiling categories $(\mathrm{OC})$ are defined in Table 1

\begin{tabular}{|lccccc|}
\hline & OC 1 & OC 2 & OC 3 & OC 4 & Total \\
\hline PD & 10 & 19 & 14 & 9 & $52(36 \%)$ \\
Stable & 21 & 18 & 14 & 39 & $92(64 \%)$ \\
Total & 31 & 37 & 28 & 48 & 144 \\
\hline
\end{tabular}

Table 4. Classification of 24 of 96 (25\%) oiled and successfully rehabilitated Kemp's ridley sea turtles Lepidochelys kempii admitted to Facility A by a prognostic scoring model. At admission, these turtles exceeded the threshold index of the prognostic scoring model associated with severe physiological derangements in cold-stunned turtles. Oiling categories (OC) are defined in Table 1

\begin{tabular}{|lc|}
\hline OC & Turtles (n) \\
\hline 1 & 4 \\
2 & 5 \\
3 & 4 \\
4 & 11 \\
Total & 24 \\
\hline
\end{tabular}

0.2275). Of 96 Kemp's ridley sea turtles with complete data $\left(\mathrm{pH}_{1} \mathrm{pO}_{2}\right.$, and $\left.\mathrm{K}\right)$ available for analysis from Facility A, 25\% exceeded the threshold index of the prognostic scoring model associated with severe physiological derangements in cold-stunned turtles (Table 4). There were no significant differences among the numbers of turtles in OCs 1 through 4 that exceeded the threshold $(\mathrm{p}=0.3206)$.

\section{DISCUSSION AND CONCLUSIONS}

Clinicopathological findings in sea turtles oiled and rescued during the DWH spill indicate that these animals were affected by various degrees of acute, nonspecific metabolic and osmoregulatory derangements. These abnormalities were likely caused by the effects of stress, dehydration, exertion, and physical exhaustion resulting from oil exposure, physical fouling, capture, and/or transport. Overt, specific correlations or differences between OCs and presence or degree of abnormalities were not observed. It should be noted that the sea turtles included in this study also may have been exposed to dispersants, which were used in large volumes within offshore areas where animals were rescued. The findings presented herein are similar to those reported by Harms et al. (2014) 
based on experimental exposure of loggerhead sea turtle hatchlings to DWH oil and dispersant. Harms et al. (2014) described dysregulatory effects on osmolality, electrolytes, and hydration status. These effects were most pronounced $4 \mathrm{~d}$ after hatchlings were exposed to a combination of oil and dispersant compared to exposure group on Day 1, control, oil, and dispersant groups. As evidenced by the high rate of survival following rescue and care in wild oiled turtles, the conditions from the DWH spill were effectively treated largely by removal of turtles from the oiled environment, cleaning of oil from external surfaces and the upper digestive tract, and supportive care including fluid, electrolyte, and glucose replacement. Although this outcome is promising for sea turtles that received care and is informative for responses to future oil spills, it is estimated that tens of thousands of sea turtles were within the vast area of the DWH spill but were not rescued (McDonald et al. 2015). Our findings suggest that many of these animals in oiled conditions may have had significant physiological derangements that threatened their survival.

Conservatively, $36 \%$ of oiled turtles of all species were subjectively assessed as substantially physiologically deranged, and $25 \%$ of oiled Kemp's ridley turtles had physiological derangements that were comparably severe to those associated with risk of mortality in cold-stunned sea turtles. Both the clinical assessment of physiological status and application of the prognostic model provided an evaluation of physiological derangements at admission based on their degree and clinical relevance. Moreover, alteration of these parameters was consistent with the physical effects of miring in oil and concerns related to hyperthermia noted in the course of field rescue of oiled turtles during the DWH spill (Stacy 2012). Actual mortality of oiled endangered sea turtles without intervention could not be ethically studied - i.e. the goal of the rescue and rehabilitation efforts was to medically intervene and save turtles - thus, it was not possible to directly evaluate the prognostic effectiveness of the applied assessment and model for oiled turtles. We acknowledge that the predictive value of this model for oiled sea turtles is likely different from that of cold-stunned turtles, given significant differences in pathophysiology between these 2 different conditions, and given that survival of treated oiled turtles was very high in comparison with treated cold-stunned turtles. Nonetheless, physiological derangements in over half of oiled turtles exceeded the threshold for mortality risk as predicted by a model based on known mortality outcome and key clinical parameters. This finding warrants concern for the fate of oiled sea turtles that were not rescued and did not receive medical care.

Differences in predicted mortality risk based on OC were not observed using this model. The analytes shown to be most predictive of survival outcome in cold-stunned turtles reflect relatively acute, nonspecific (but biologically significant) physiological changes that can be confounded by other stressors. For example, at-sea capture, handling, immediate treatment, and subsequent transport of oiled turtles to rehabilitation centers likely influenced the relevant blood parameters and confounded effects of oiling and environmental condition. In addition, cloacal temperatures at admission were not reflective of body temperature upon capture because treatment began immediately upon capture. Oil was removed, and turtles were placed into a protected environment on the capture boat. Upon reaching shore, turtles were transported in air-conditioned vehicles. Thus it is reasonable to assume that body temperature decreased between capture and admission, which may have further obscured differences among OCs. This consideration is especially relevant for more heavily oiled turtles, given field observations related to risk of hyperthermia (Stacy 2012), because higher body temperature decreases blood $\mathrm{pH}$ in reptiles and likely worsens acidosis (Campbell 2006). Specific study of the turtles' physiological state at capture would have required atsea blood collection and analysis that was not feasible during a disaster situation and rescue response.

Stress responses to transportation of oiled sea turtles may have contributed to some of the physiological changes in oiled turtles and differences between facilities. However, Hunt et al. (2016) did not find clinically relevant physiological changes in juvenile Kemp's ridley sea turtles after up to $26 \mathrm{~h}$ of transport, although animals in that study were larger and had been acclimatized to captivity for months prior to transport. While the possible confounding effects of handling and transport on our data cannot be dismissed, it also cannot be assumed that the observed derangements were solely due to handling and transport.

\section{Interpretation of clinicopathological findings in oiled turtles}

The initially increased WBC and heterophil concentrations in the absence of any morphological WBC abnormalities, rapid subsequent normalization of WBC concentrations, and upward trends in lymphocytes and eosinophils are most consistent with an 
initial physiological stress response (Campbell 2006, Hunt et al. 2016), although an acute inflammatory component could have contributed to the observed heterophilias at admission. Antigenic stimulation in captivity may have caused increasing lymphocytes, monocytes, and eosinophils, respectively.

Increasing total solids, TP, and ALB during rehabilitation may reflect increased feeding after initial anorexia at admission or greater food availability while in captivity, effects of captive diet composition, or recovery of initially impaired liver function presumptively associated with anorexia, as observed by Innis et al. (2009) in cold-stunned turtles during rehabilitation. Since acute inflammation may have been present at admission, hypoalbuminemia as part of an acute phase protein response may also have contributed to initially low concentrations.

As with the predominant leukogram findings, hyperglycemia in sea turtles is consistent with a physiological stress response (Hunt et al. 2016) and is commonly observed in sea turtles admitted to rehabilitation centers (Innis et al. 2007, 2009, Keller et al. 2012). Considerations for hypoglycemia in oiled turtles included anorexia and physical exhaustion.

Stable or decreasing trends of $\mathrm{Ca}$, increasing $\mathrm{P}$, and resulting decreasing $\mathrm{Ca}: \mathrm{P}$ ratio may be attributed to diet, changes in sunlight exposure, and/or bone and tissue growth in juvenile sea turtles fed a captive diet. Similar concentrations of these analytes have been previously reported for sea turtles (Innis et al. 2009, Kelly et al. 2015). The upward trend of the Ca:P ratio at Facility $\mathrm{A}$ and downward trend at Facility $\mathrm{B}$ in green turtles was likely associated with differences in dietary supplementation. Ca:P ratio often decreases in growing Kemp's ridley turtles during rehabilitation likely due to growth and diet differences during captivity (Innis et al. 2009).

Initially elevated electrolytes and UA indicate altered fluid or osmoregulatory balance, dehydration, and/or reduced renal function. However, values generally improved rapidly during hospitalization. The variability of plasma versus whole blood K data is likely caused by methodology differences. The observation of variable BUN concentrations but stable (Facility A) or decreasing (Facility B) manually calculated osmolality throughout rehabilitation suggests that osmolality should be determined by analytical measurement in sea turtles rather than by manual calculation. Manual calculation relies on $\mathrm{Na}$, glucose, and BUN, which in this study exhibited downward ( $\mathrm{Na}$, glucose) or variable (BUN) trends in oiled turtles, thus resulting in persistently (and likely artificially) high calculated osmolality results.
The variability of trends in cholesterol may be associated with stress-related lipid metabolism or nonfasted samples, while increasing triglyceride trends likely reflected abundance of nutrition in captivity.

Variations in tissue enzyme activities (ALP, ALT, AST, CK, LDH) were consistent with nonspecific tissue injury, given their wide tissue distribution in sea turtles (Anderson et al. 2013, Petrosky et al. 2015). For tissue enzyme elevations at admission, considerations included effects from exertion, capture, and/or handling and transport. During rehabilitation, elevations were likely associated with growth of immature turtles and effects of confinement or problems that developed during captivity (Innis et al. 2009, Anderson et al. 2013, Petrosky et al. 2015). Considering these confounding effects, statistically significant differences in these enzyme activities that were inconsistently observed at different time points during rehabilitation among OCs do not allow for relevant clinical conclusions with regard to adverse effects from oiling.

Metabolic acidosis that was observed in the majority of oiled turtles after rescue and transport can be attributed to stress, overexertion, lethargy, poor tissue perfusion, dehydration, and/or elevated body temperatures. Turtles admitted to Facility B had comparatively more pronounced metabolic derangements that were disproportionately out of range compared to turtles admitted to Facility A, likely attributable to confounding effects of capture, handling, and transport duration. Respiratory acidosis is generally caused by hypoventilation, which may have developed during oiling and capture, or there may have been other inhibitors of respiratory function. Since respiratory alkalosis results from hyperventilation, the low number of turtles with this condition may have had stimulation of their respiratory center from severe metabolic acidosis or heat.

\section{Comparison with previously reported oil effects}

In contrast to results reported for birds exposed to polycyclic aromatic hydrocarbons in crude oil (Troisi et al. 2007), we found no evidence of hemolytic anemia or oxidative erythrocyte damage during the DWH spill, suggesting species differences in susceptibility to this effect. Our findings also contrast with those from a previous experimental study on loggerheads, which reported a $50 \%$ decrease in $\mathrm{RBC}$ counts from petroleum exposure (Lutcavage et al. 1995). However, there are 2 notable caveats to this previous study that should be considered with regard to this observation. First, ethylenediaminetetraacetic acid 
(EDTA), which causes artefactual hemolysis in many chelonian species, was used as an anticoagulant. Second, no concurrent decrease in PCV was observed, as would be expected with true anemia.

Various degrees of non-hemolytic anemia were observed in oiled sea turtles rescued during the DWH spill, but this was an inconsistent finding that was variable in onset, complicating some elements of interpretation. Various degrees of dehydration (which is difficult to assess and quantify clinically in sea turtles), osmoregulatory changes associated with enclosure water of different salinities and mineral composition, and other factors associated with capture and captivity may have contributed to this variability. Also, some of the cases with low PCV of unknown cause may have been the result of lymph contamination during sample collection, which can occur even with experienced personnel.

Based on a previous study that suggested possible salt gland dysfunction in 2 loggerhead turtles that were experimentally exposed to oil (Lutcavage et al. 1995), salt gland dysfunction was considered as a possible contributing cause of the observed electrolyte abnormalities in oiled turtles. However, upon review of this previous study, salt gland dysfunction was not quantitatively evaluated, and supportive clinicopathological evidence was not presented. Therefore, any dysfunction of sea turtle salt gland physiology from oil exposure remains speculative, and specific data to support an effect are not available in the current literature. The function of the salt glands is not completely understood, but their role in osmoregulation has been investigated and includes excretion of $\mathrm{Na}, \mathrm{K}$, and $\mathrm{Cl}$ (Marshall \& Cooper 1988, Nicolson \& Lutz 1989). The correlation of electrolyte concentrations in plasma compared to lacrimal fluid is complex and not fully understood to date, since the excretory rate of the lacrimal gland appears to be highly variable (Cowan 1990). Reina \& Cooper (2000) observed an increase of plasma $\mathrm{Na}$ and osmolality within minutes after exposure of green turtle hatchlings to high salt concentrations and reported inhibitory effects of adrenaline and the cholinergic agonist methacholine on salt gland excretion. The results of this study provide evidence that stress may impair salt gland activity. However, the effects of corticosterone on salt gland function in sea turtles have not been described to date.

The limited comprehensive electrolyte data $(\mathrm{Na}, \mathrm{K}$, $\mathrm{Cl}$ ) in Facility A turtles at admission ( $\mathrm{n}=26 / 176$ for chemistry data and $\mathrm{n}=30 / 171$ for i-STAT data) revealed 5 turtles with concurrently increased concentrations of all 3 electrolytes by chemistry analysis and no turtles with concurrently increased concentrations of all 3 electrolytes by i-STAT analysis. Orós et al. (2011) reported salt gland adenitis as the cause of stranding in 2 loggerhead turtles with marked hypernatremia (mean of $218 \pm 2.5 \mathrm{mmol} \mathrm{l}^{-1}$ ) and hyperchloridemia (mean $187 \pm 5 \mathrm{mmol}^{-1}$ ). Among oiled turtles in the current study, maximum concentrations for $\mathrm{Na}$ were $174 \mathrm{mmol} \mathrm{l}^{-1}$ (1 turtle of OC2 in time period 11 to $20 \mathrm{~d}$ at Facility B) and for Cl $149 \mathrm{mmol} \mathrm{l}^{-1}$ (1 turtle of OC2 at admission to Facility A), respectively, which were single observations above the mean/ median for a given time period. These data do not support the assumption of specific adverse effects of oil on salt gland function; however, the possibility of some effect, such as a temporary effect at time of admission, or a more significant effect if turtles had not received treatment, should be considered.

No specific toxicological or long-term effects attributed to oiling were evident in any of the clinicopathological analytes from oiled turtles. The elevations of non-specific tissue enzyme activities and other analytes varied across OCs and over time, and most were explainable by captive conditions and growth of juvenile turtles. However, the dose and duration of petroleum exposure was unknown for these turtles, and additional exposure was prevented upon rescue; thus, potential effects resulting from more chronic exposure cannot be concluded from our findings.

Clinical evaluation and treatment of oiled wildlife provides direct mitigation of harm resulting from oil spills and is invaluable to understanding effects on animals that cannot be reached for intervention and care. Only a fraction of affected animals may be directly observed, especially in marine spills. The clinicopathological abnormalities in rescued oiled turtles during the DWH spill indicated stress, exertion, physical exhaustion, and dehydration related to oiling, capture, and transport. These findings substantiate field observations related to physical effects of oil and oiling of sea turtle habitat (Stacy 2012). In summary, a substantial percentage of hospitalized turtles affected by the DWH oil spill had severe physiological derangements that likely benefited from medical intervention. Assuming that such derangements were also present in oiled turtles that were not hospitalized, a significant percentage of those turtles likely died at sea. In addition to these acute considerations, a thorough accounting of injuries to sea turtles during the DWH spill must include potential toxicological and long-term exposure effects, and threats posed by the severity of environmental conditions (DWH Trustees 2015, Section 4.8). 
Acknowledgements. The findings and conclusions in this presentation are those of the authors and do not necessarily represent the view of NOAA and DOI or of any other natural resource Trustee for the BP/Deepwater Horizon Natural Resources Damage Assessment (NRDA). We thank all volunteers, veterinarians, technicians, animal care staff, field responders, and government agency personnel that were invaluable to the rescue and rehabilitation of sea turtles during the BP Deepwater Horizon oil spill. Rehabilitation facilities included Audubon Nature Institute (New Orleans, LA), Gulf World Marine Park (Panama City, FL), Institute for Marine Mammal Studies (Gulfport, MS), Clearwater Marine Aquarium (Clearwater, FL), Disney Animal Kingdom (Lake Buena Vista, FL), Florida Aquarium (Tampa, FL), Gulfarium (Fort Walton Beach, FL), Mote Marine Laboratory and Aquarium (Sarasota, FL), and SeaWorld (Orlando, FL). Special thanks to Dr. Shane Boylan, Dr. Craig Harms, Dr. Terry Norton, Dr. Gregory Lewbart, Dr. Conny Chevis, Marina Piscitelli, Constance Merigo, and Dr. Allison Tuttle. Veterinarians, technicians, biologists, and other vital personnel from throughout the country supported these facilities and were essential to response efforts. We also thank the laboratory staff at University of Miami Avian and Wildlife Laboratory and Antech Diagnostics for technical assistance. We also thank Dr. Bryan Wallace for his thoughtful review and comments.

\section{LITERATURE CITED}

Anderson ET, Harms CA, Stringer EM, Cluse WM (2011) Evaluation of hematology and serum biochemistry of cold-stunned green sea turtles (Chelonia mydas) in North Carolina, USA. J Zoo Wildl Med 42:247-255

Anderson ET, Socha VL, Gardner J, Byrd L, Manire CA (2013) Tissue enzyme activities in the loggerhead sea turtle (Caretta caretta). J Zoo Wildl Med 44:62-69

Bolten AB, Bjorndal KA (1992) Blood profiles for a wild population of green turtles (Chelonia mydas) in the southern Bahamas: size-specific and sex-specific relationships. J Wildl Dis 28:407-413

Camacho M, Luzardo OP, Boada LD, Jurado LF, Medina M, Zumbado M, Orós J (2013) Potential adverse health effects of persistent organic pollutants on sea turtles: evidences from a cross-sectional study on Cape Verde loggerhead sea turtles. Sci Total Environ 458-460:283-289

Campbell TW (2006) Clinical pathology of reptiles. In: Mader DR (ed) Reptile medicine and surgery, $2^{\text {nd }}$ edn. Saunders Elsevier, St. Louis, MO, p 453-470

Casal AB, Camacho M, Lopez-Jurado LF, Jsute C, Orós J (2009) Comparative study of hematologic and plasma biochemical variables in Eastern Atlantic juvenile and adult nesting loggerhead sea turtles (Caretta caretta). Vet Clin Pathol 38:213-218

Cowan FBM (1990) Does the lachrymal salt gland of Malaclemys terrapin have a significant role in osmoregulation? Can J Zool 68:1520-1524

DWH Trustees (2015) Deepwater Horizon oil spill final programmatic damage assessment and restoration plan and programmatic environmental impact statement. www.gulfspillrestoration.noaa.gov/restoration-planning/ gulf-plan/

Harms CA, McClellan-Green P, Godfrey MH, Christiansen EF, Broadhurst HJ, Godard-Codding C (2014) Clinical pathology effects of crude oil and dispersant on hatch- ling loggerhead sea turtles (Caretta caretta). Proceedings of the International Association for Aquatic Animal Medicine. 45th Annual IAAAM Conference, May 17-22, 2014, Gold Coast, Australia. www.vin.com/apputil/content/ defaultadv1.aspx?pId=11397\&meta=Generic \&catId=358 84\&id=6251903 (accessed 12 May 2016)

Harvey JW (2012) Veterinary hematology. A diagnostic guide and color Atlas. Elsevier Saunders, St. Louis, MO

Hunt KE, Innis CJ, Kennedy A, McNally K, Davis D, Burgess E, Merigo C (2016) Assessment of ground transportationrelated stress in juvenile Kemp's ridley sea turtles (Lepidochelys kempii). Conserv Physiol 4:cov071

* Innis CJ, Tlusty M, Merigo C, Weber ES (2007) Metabolic and respiratory status of cold-stunned Kemp's ridley sea turtles (Lepidochelys kempii). J Comp Physiol B Biochem Syst Environ Physiol 177:623-630

* Innis CJ, Ravich JB, Tlusty MF, Hoge MS and others (2009) Hematologic and plasma biochemical findings in coldstunned Kemp's ridley turtles: 176 cases (2001-2005). J Am Vet Med Assoc 235:426-432

*Keller KA, Innis CJ, Tlusty MF, Kennedy AE, Bean SB, Cavin JM, Merigo C (2012) Metabolic and respiratory derangements associated with death in cold-stunned Kemp's ridley turtles (Lepidochelys kempii): 32 cases (2005-2009). J Am Vet Med Assoc 240:317-323

Kelly TR, Braun McNeill J, Avens L, Goodman Hall A and others (2015) Clinical pathology reference intervals for an in-water population of juvenile loggerhead sea turtles (Caretta caretta) in Core Sound, North Carolina, USA. PLOS ONE 10:e0115739

* Lutcavage ME, Lutz PL, Bossart GD, Hudson DM (1995) Physiologic and clinicopathologic effects of crude oil on loggerhead sea turtles. Arch Environ Contam Toxicol 28: $417-422$

Marshall AT, Cooper PD (1988) Secretory capacity of the lachrymal salt gland of hatchling sea turtles, Chelonia mydas. J Comp Physiol B Biochem Syst Environ Physiol 157:821-827

McDonald T, Witherington B, Schroeder B, Stacy B (2015) Density estimates of surface-pelagic (oceanic) juvenile sea turtles oiled by MC252 spill. DWH NRDA Sea Turtle Technical Working Group Report. Prepared for NOAA Assessment and Restoration Division. https://pubdwhdatadiver.orr.noaa.gov/dwh-ar-documents/894/DWHAR0149417.pdf (accessed 12 May 2016)

Nicolson SW, Lutz PL (1989) Salt gland function in the green sea turtle Chelonia mydas. J Exp Biol 144:171-184

* Orós J, Calabuig P, Déniz S (2004) Digestive pathology of sea turtles stranded in the Canary Islands between 1993 and 2001. Vet Rec 155:169-174

* Orós J, Camacho M, Calabuig P, Arencibia A (2011) Salt gland adenitis as only cause of stranding of loggerhead sea turtles Caretta caretta. Dis Aquat Org 95:163-166

* Petrosky KY, Knoll JS, Innis C (2015) Tissue enzyme activities in Kemp's ridley turtles (Lepidochelys kempii). J Zoo Wildl Med 46:637-640

R Core Team (2015) R: a language and environment for statistical computing. R Foundation for Statistical Computing, Vienna

* Reina RD, Cooper PD (2000) Control of salt gland activity in the hatchling green sea turtles, Chelonia mydas. J Comp Physiol B Biochem Syst Environ Physiol 170: 27-35

Shigenaka G (ed) (2003) Oil and sea turtles: biology, planning, and response. National Oceanic and Atmospheric 
Administration (NOAA), National Ocean Service, Office of Response and Restoration, Seattle, WA. http://response. restoration.noaa.gov/sites/default/files/Oil_Sea_Turtles. pdf (accessed 21 December 2015)

Stacy B (2012) Summary of findings for sea turtles documented by directed captures, stranding response, and incidental captures under response operations during the BP DWH MC252 oil spill. DWH NRDA Sea Turtle Technical Working Group Report. Prepared for NOAA Assessment and Restoration Division. https://pubdwhdatadiver.orr.noaa.gov/dwh-ar-documents/894/DWHAR0149670.pdf (accessed 12 May 2016)

Stacy NI, Innis CJ, Hernandez JA (2013) Development and evaluation of three mortality prediction indices for cold-

Editorial responsibility: Tracey Goldstein (Guest Editor), Davis, California, USA stunned Kemp's ridley sea turtles (Lepidochelys kempii). Conserv Physiol 1:cot003

Stockham SL, Scott MA (2008) Fundamentals of veterinary clinical pathology. Blackwell Publishing, Ames, IA

Troisi G, Borjesson L, Bexton S, Robinson I (2007) Biomarkers of polycyclic aromatic hydrocarbon (PAH)-associated hemolytic anemia in oiled wildlife. Environ Res 105:324-329

Vargo S, Lutz P, Odell D, Van Vleet E, Bossart G (1986) Effects of oil on marine turtles, Vol 1-3. Final Report MMS No. 14-12-0001-30063. Florida Institute of Oceanography, St. Petersburg, FL

* Witherington BE (2002) Ecology of neonate loggerhead turtles inhabiting lines of downwelling near a Gulf Stream front. Mar Biol 140:843-853

Submitted: May 12, 2016; Accepted: September 6, 2016 Proofs received from author(s): October 17, 2016 